\title{
ISLE-inspired design laboratory transformation at Princeton University: Year two results
}

\author{
Katerina Visnjic ${ }^{1}$, Catherine Riihimaki ${ }^{2}$, Carolyn Sealfon ${ }^{2}$, and Evelyn Laffey ${ }^{2}$ \\ ${ }^{1}$ Princeton University, Department of Physics, \\ Jadwin Hall, Washington Rd., Princeton, NJ 08544 \\ ${ }^{2}$ Princeton University, Council on Science and Technology \\ Lewis Library, Washington Rd., Princeton, NJ 08544
}

\begin{abstract}
In an effort to enhance the traditional calculus-based introductory physics course at Princeton University, an Investigative Science Learning Environment (ISLE) inspired lab transformation is underway, currently in its $3^{\text {rd }}$ year. In the first two years the new curriculum was implemented in a subset of the lab sections, while the remaining sections performed traditional lab activities. To assess the effectiveness of the new design labs, we conducted interviews with the students, and administered a pre/post attitudes survey. The primary questions guiding the evaluations are i) what are the students' lived experiences in the new lab, ii) how did students relate physics to their everyday lives, iii) what are the student-reported short and long term learning gains of the skills developed in design labs, and iv) what are the differences in attitudes between students in the new and traditional labs. Here we describe the pedagogical approach used in the transformed sections and show results from the interviews and survey.
\end{abstract}

PACS: $01.50 . \mathrm{Qb}, 01.40 . \mathrm{Di}, 01.40 . \mathrm{Fk}$

\section{INTRODUCTION}

In an effort to enhance the traditional calculus-based introductory physics course for engineers at Princeton University, an Investigative Science Learning Environment (ISLE) inspired lab transformation is underway. ISLE is a research-validated method [1] that engages students in the process of scientific inquiry, and students are guided to design their own experiments. In addition to yielding high learning gains in conceptual and quantitative understanding, ISLE programs have been shown to improve the relative performance of women and under-represented minorities, as well as their retention rate in STEM fields [2].

Over 300 students take the course in question, PHY103/104, the two-semester physics requirement for all engineering students. For the majority of PHY103/104 students, this will be the only physics course they take at Princeton.

The format of the course is slightly different from most institutions, as there is only one hour-long lecture each week. It is intended to give an overview of the week's topic and present a series of lecture demonstrations. Most of the content is addressed by three one-hour classes of $\sim 25$ students, taught by faculty. Finally, there is one three-hour lab, led by graduate teaching assistants (TAs), totaling 7 hours of class per week.

The transformation was piloted during the academic year 2013-14, and involved transforming two out of the 18 lab sections, taught by Visnjic and two TAs. By Spring 2015, half of all lab sections followed the new curriculum and were taught by four TAs. We have named the sections
Table 1. Chronology of events.

\begin{tabular}{|l|l|l|}
\hline AY & Fall, PHY103 & Spring, PHY104 \\
\hline $2013-14$ & 2 new $/ 18$ lab sections & $2 / 16,1^{\text {st }}$ interviews \\
\hline $2014-15$ & $8 / 18$, attitudes survey & $8 / 16,2^{\text {nd }}$ interviews \\
\hline
\end{tabular}

"new labs" and "classic labs," respectively, when referring to the transformed and traditional lab sections.

As we move to complete the transformation in the coming academic year 2015-16, involving all $\sim 10$ TAs, we are interested in assessing the effectiveness of the new curriculum in the Princeton environment. In particular, we seek to compare the self-reported learning gains and attitudes of students in new labs versus classic labs, and to determine the extent to which the effects are long-term. To this end, we conducted individual interviews of students in the new lab sections in Spring ' 14 and ' 15 , and administered a pre/post learning attitudes survey to all students in Fall '14. Table 1 summarizes the events.

\section{PEDAGOGY}

In the new lab curriculum, students are asked to design their own experiments to answer a specific question. In contrast, in the classic labs students are provide with a prescribed set of procedures and analysis methods to follow. The ISLE framework was adopted in the new labs because of its unique approach in soliciting students' predictions and engaging them in the process of science. In contrast to other inquiry methods, ISLE never asks students to make predictions based on their intuition. Rather, they are always based on the specific model or hypothesis that is being tested. Thus the comparison of the prediction to the 
outcome is not a direct reflection of their intuition, but is a test of the model, and this minimizes if not eliminates possible feelings of failure [3].

For example, in one lab we asked the students to test the hypothesis that fluid resistance is independent of velocity. The students had already learned in class that friction between two surfaces does not depend on their relative speed, but not having learned about fluid dynamics in the course, most students did not realize that the hypothesis to be tested is in fact false.

The instructors had discussed this activity in advance and had come up with one way to contradict the hypothesis, namely to video record a ball as it falls in a container of water and observe how it reaches terminal velocity with the frame-by-frame video analysis software. They were pleasantly surprised to see that the students collectively came up with four different and valid ways of testing the hypothesis, and only one group used the same method as the instructors. The most original experiment involved tying a ball to a spring-scale with a string and pulling it up through the water at a slow constant speed and then again at a faster constant speed, reading the force on the scale each time. Their measurements revealed that the two forces were not the same, contrary to the prediction; they were thrilled at successfully disproving the hypothesis.

In the new labs we introduced a grading rubric based on their demonstration of a list of "scientific abilities" [4] given to them in advance. In contrast, the classic labs do not have grading rubrics. An example of an ability that is specific to a hypothesis-testing type of experiment like the one described above is "[student] is able to make a reasonable prediction based on a hypothesis." This is an important step for all lab groups to do, regardless of the specific experiment. The list of scientific abilities comprises a rubric that is flexible enough to allow for creativity in experimental design yet still specific enough to provide scaffolding so that students know what is expected of them.

\section{METHODOLOGY}

During the Spring 2014 and 2015 semesters, students enrolled in the PHY104 "new lab" sections were invited to participate in semi-structured qualitative interviews. These are described in section III.A.

In order to have a direct comparison of the attitudes of students in the new and classic lab, all students enrolled in PHY103 in Fall 2014 were given a pre- and post-semester survey adapted from the Colorado Learning Attitudes about Science Survey for Experimental Physics (E-CLASS) [6]. The survey is described in section III.B.

\section{A. Student Interviews}

Of the 36 students in the two new lab sections in Spring 2014, seven were interviewed. All students were enrolled in their first year of their undergraduate program and all were pursuing the BSE degree. Four of these seven students returned for a follow-up interview in Spring 2015, at the end of their sophomore year. Of the 158 students in new labs in Spring 2015, four were interviewed. Three were first-year students and one a second-year, and all were pursuing the BSE degree.

The semi-structured interview protocol was adapted from the literature [5]. The questions that guided the first interviews of the students centered around how the students' ideas about and skills in physics changed as a result of taking PHY103/104. Examples of questions from the first interview are:

- Tell me about your experience in PHY 103 lecture, precept, and lab.

- What are your thoughts on the teaching methods used in the various components of the PHY course?

- Have your ideas about physics changed somehow as a result of taking PHY lab? Please explain.

For the second interview, we were interested in understanding whether there were self-reported long-term gains from the new lab curriculum. The questions focused on what content topics and skills from PHY103/104 the students were still using, and to what extent the transfer of habits of mind that they articulated in their first year continued in their second year. Examples of questions from the second interview are:

- Please comment on the skills you have gained as a result of taking PHY; for example, identifying patterns in data, recognizing a sound argument and appropriate use of evidence, developing a logical argument, etc.

- To what extent have you applied those skills to your everyday life? If at all, please provide an example.

All interviews were conducted in the last weeks of the semester, by three researchers not involved in teaching the course. The interviews with video and audio recorded. Upon completion of the interviews, the researchers analyzed the data based on a non-linear framework [7].

The researchers then met to discuss emergent themes and define corresponding codes. They used open coding [8] to inductively code the video data into broad categories and then refined them into subcategories. After coding three interviews, the researchers again met to verify that the emergent coding scheme accurately captured the students' perspective on the new lab experience and resolve any discrepancies.

Each researcher then returned to the interview video data on their own to identify "critical events" where the discourse addressed our guiding research questions. These events were then transcribed and coded using the same coding scheme.

\section{B. Attitudes Survey}

The pre/post survey administered consisted of 25 statements, 23 of which were taken from the E-CLASS Part 1: Attitudes About Experimental Physics. Two new statements were added to probe learning goals of the new 
lab curriculum not directly addressed by the existing statements. The wording of the added statements, shown in Table 2 in section IV, was heavily based on a statement in the E-CLASS relating to analyzing data.

The survey was administered in class in the first and second-to-last classes of the semester. The students were not given advance notice. Of the 315 students, 236 took the pre-survey and 173 took the post-survey. Only students who took both surveys were included in the analysis, a total of 157, of which 82 were from classic lab sections and 75 from new lab sections.

The pre- and post-semester replies of students in new and classic labs were compared. Each question was considered separately, and the common language effect size (CLEF) of new and classic distributions from the MannWhitney U Test was determined. A CLEF of 0.5 implies the two sets come from the same distribution, and $<0.4$ or $>0.6$ is considered a statistically significant difference.

\section{DATA AND RESULTS}

Interviews. Preliminary analysis has been conducted on the interview data. Three categories of codes emerged as students described their experience in PHY103/104 in Spring 2014: support, content and transfer. As students' reflected on their lived experiences in the course, they most often discussed feeling supported. The support enabled them to actively participate in class and overcome cognitive and affective hurdles. When asked about the relation of physics to their everyday lives and cognitive learning gains, the students often provided examples that carried physics content and course skills into other facets of their lives. Because the support and transfer categories directly answer our guiding research questions, we discuss only these two categories in the following paragraphs. The support category was subdivided into emotional (affective) and technical support, and the transfer category was subdivided into transfer of course content and transfer of habit of mind. The same codes were found to apply to the interviews conducted in 2015 .

The support code is defined as: Students discussing the support they receive from educators, peers, and others. As they reflected on their lived experiences in the PHY lab, they often noted that while the new labs were challenging, they felt supported by members of the teaching team and their peers. They also reflected on gaining support from their family, as they struggled with PHY and other courses. The support garnered from faculty and their peers assisted with acquiring content knowledge, as well as enhancing their overall affect about physics. The following excerpts of interview transcripts provide examples of the support code.

"I really liked physics this semester. It was like one of my favorite classes. Um, and I wish that there would be more classes with that kind of support and a teacher that cares about you doing well, and cares about her teaching you." [Michelle, 2014]
"One of the hardest decisions with choosing to go with the experimental section for 104, because the labs would take up at least all 3 hours and were very challenging. But at the same time, I think all of the challenges that the experimental section brought were very rewarding." [Matt; 2014]

The transfer code is defined as: Students discussing the conceptual knowledge or procedural skills gained from PHY 103/104 and provide examples of application in everyday life. Students offered several examples of how Physics relates to their everyday lives, from conventional applications in other courses - like applying light and lens properties to understand vision in a Neuroscience course and applying electricity concepts to understand circuits in a Computer Science course - to applications in non-STEM courses, and even to applications outside of academia - like using electricity concepts to rewire a house with the student's father. The following excerpts of interview transcripts illustrate the transfer code.

"I've noticed quite a bit of connection with my writing seminar. Um. Every time I kind of read a person's essay I'm able to understand, I think I have a much better outlook on what assumptions they're using, just the underlying premises of their argument, and I feel like with physics somehow I can better take that apart, um, and that's been a really interesting process for me, because I always kept those two as being very distinct from one another, English and STEM. So the fact that they seem to be intersecting - is quite fascinating." [Helen, 2014]

"I guess that now I'm a lot more critical about the evidence and I'm going to read something in the paper and I'm ... going to be thinking ... what type of assumptions did they make saying that?... So, I guess I'm a lot more critical ...does this make sense to me?" [Charles, 2014]

Students in the Spring 2014 sections had more examples of how the Physics related to their lives. The 2015 students anticipated that some concepts and skills would continue to be important in their engineering studies, such as problemsolving skills. However, they did not draw widespread connections to their personal lives in the same way that the Spring 2014 cohort did.

Long term gains. The students from the Spring 2014 cohort who returned for a second interview in their sophomore year indicated that they valued skills such as data analysis techniques used in the new labs. They reported feeling confidence in solving complex and openended problems. While recognizing that these types of problems can be difficult and intimidating initially, since they had successfully tackled those problems before, they felt that they could continue to be successful.

Students also reported that PHY103/104 had changed their way of thinking, such that the thought processes became natural habits of mind in their sophomore year. 
Some students could identify specific habits of mind that continued from PHY103/104, like identifying assumptions. Others felt more generally that they simply felt smarter and more confident from having taken PHY103/104.

Few students reported that specific content was important in their studies sophomore year. This may be because they had yet to take courses that applied physics concepts or do research, perhaps because they were primarily intended computer science majors. Nevertheless, almost all students felt that the physics courses should continue to be a requirement for all engineering students.

Attitudes Survey. Out of the 25 statements on the presurvey, all of the CLES's were between 0.40-0.60, indicating that the students in new and classic labs did not have statistically different attitudes at the beginning of the semester. On the post-survey, nine statements showed a significant difference. Six of these are shown in Table 2 and Figure 1. Not surprisingly, the most significant statements were the ones that probed the lab skills targeted in the design component of the new labs.

Figure $1 \mathrm{~b}$ shows an example of a statement where the attitudes of students in the classic labs shifted significantly towards being more novice (CLES 0.39), while those of

Table 2. Six Most Significant Statements

\begin{tabular}{|l|c|c|}
\hline \multicolumn{1}{|c|}{ Statement } & CLES & $\sigma$ \\
\hline $\begin{array}{l}\text { If the lab guide doesn't give clear } \\
\text { directions for constructing a mathematical } \\
\text { model to describe my experiment, I am not } \\
\text { sure how to construct one myself. (Added) }\end{array}$ & .80 & 6.5 \\
\hline Shown in Figure 1a. (Added) & .71 & 5.0 \\
\hline $\begin{array}{l}\text { If the lab guide doesn't give clear } \\
\text { directions for analyzing data, I am not sure } \\
\text { how to choose an appropriate method to } \\
\text { analyze my data. (ECLASS) }\end{array}$ & .70 & 4.5 \\
\hline Shown in Figure 1b. (ECLASS) & .66 & 3.5 \\
\hline $\begin{array}{l}\text { When doing an experiment, I try to } \\
\text { understand how the experimental setup } \\
\text { works. (ECLASS) }\end{array}$ & .64 & 3.0 \\
\hline $\begin{array}{l}\text { When I approach a new piece of lab } \\
\text { equipment, I feel confident I can learn how } \\
\text { to use it well enough for my purposes. } \\
\text { (ECLASS) }\end{array}$ & .61 & 2.5 \\
\hline
\end{tabular}

[1] E. Etkina and A. Van Heuvelen, Reviews in PER 1, 2007.

[2] S.W. Brahmia, in Proceedings of PERC, Syracuse, 2006, edited by C. Henderson, p. 7.

[3] A. Madsen, S.B. McKagan, and E.C. Sayre, Phys Rev ST-PER (to be published), arxiv.org/abs/1403.6522.

[4] E. Etkina et al., Phy Rev ST-PER 2, 020103, 2006.

[5] M.R. Villasenor and E. Etkina, in Proceedings of PERC, Syracuse, 2006, edited by L. McCullough, 205.
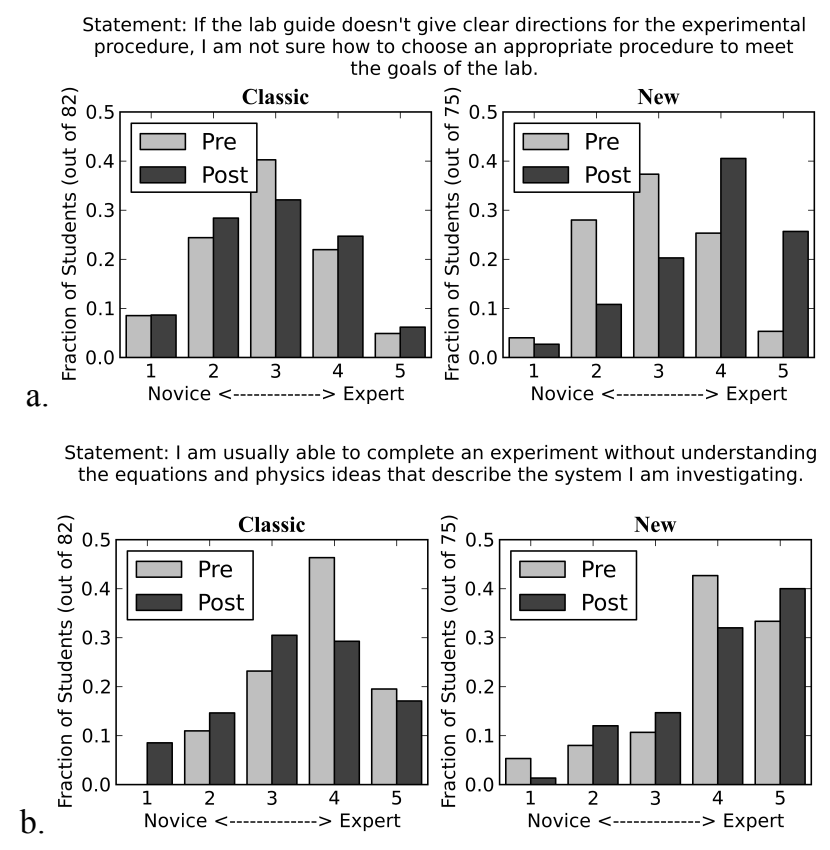

FIG 1. Two examples of attitudes survey results. The presemester results show no significant difference between classic and new lab sections, while the post distributions have CLES's of 0.71 and 0.66 , respectively.

students in the new labs shifted slightly towards more expert-like. The post-semester results have a CLES of 0.66. There were no statements for which the classic labs had a more expert-like attitude than the new labs.

\section{CONCLUSION}

Student interviews and a pre/post learning attitudes survey were used to assess the experience of the new ISLEinspired lab curriculum in PHY103/104. From the interviews we found students to be positively impacted by the increased faculty-student interaction afforded by the new labs, and the opportunity to engage in physics research and to acquire habits of mind that are applicable to other facets of their lives. Further, we found that they selfreported increased learning gains in the short and long term. This is consistent with the data from the attitudes survey, which showed a significant increase in experimental skills and attitudes towards science from students in the new labs as compared with students in the classic labs.

[6] B.M. Zwickl, N. Finkelstein, and H.J. Lewandowski, in Proceedings of PERC, Portland, 2013, edited by P. Engelhardt, $\mathrm{p} 442$

[7] A.B. Powell, J.M. Francisco, and C.A. Maher, Journal of Mathematical Behavior 22, 405 (2003).

[8] A. Strauss and J. Corbin, Basics of Qualitative Research: Techniques and Procedures for Developing Grounded Theory (Sage Publications, CA, 1998). 